\title{
GALLARDO PAÚLS, BEATRIZ (2007): PRAGMÁTICA PARA LOGOPEDAS. CÁDIZ, UNIVERSIDAD DE CÁDIZ, 235 PÁGS.
}

\author{
Sonia MAdRID CÁNOvas \\ Universidad de Murcia \\ sonja@um.es
}

El primer capítulo de Exploraciones en neuropsicología cognitiva de Alan J. Parkin (1999) se inicia con una cita del escritor y guionista británico Alan Bennet (Writing Home, 1994) en la que narra cómo su madre está viendo una amplia panorámica de Somerset y aunque quiere decir «iQué vista más grandiosa!» lo que realmente enuncia es «iQué pedazo de sobretodo!». De las ovejas que se divisan desde lo alto de la colina de Weston comenta: «Sé lo que son, pero no sé cómo se llaman!». «Así pues», refiere Alan, «mi madre es seguidora de Wittgenstein». Esta anécdota sirve para introducir el principio fundamental que vertebra toda la obra de Parkin: una de las maneras más sencillas de entender el funcionamiento de un sistema es observar lo que pasa cuando el sistema falla. Pues bien, este mismo principio es el que subyace en el libro Pragmática para Logopedas de Beatriz Gallardo Paúls editado por el Servicio de Publicaciones de la Universidad de Cádiz, pero aplicado, en esta ocasión, a los fundamentos teóricos de la pragmática. Es un recorrido excelente, muy novedoso y de doble sentido el que realiza esta profesora de Lingüística General desde la teoría pragmática a la aplicación clínica y viceversa. Aunque la autora aboga insistentemente por la necesidad de introducir una pragmática aplicada en la teorización lingüística que a menudo se les hace a los logopedas, creo, sinceramente, que en el título deberían incluirse otros destinatarios potenciales que, desvinculados de la práctica clínica, les sería igualmente útil para entender y profundizar en términos y aspectos pragmáticos relevantes en la comunicación ordinaria.

La obra se articula en siete capítulos precedidos de una introducción teórica sobre algunos lugares comunes de la lingüística clínica y la reivindicación de un enfoque pragmático con una evaluación bien fundamentada para pasar a exponer mediante casos específicos, la mayoría procedentes del corpus PerLA (Gallardo y Sanmartín, 2005; Gallardo y Moreno 2005; Garayzábal, 2005; Hernández, Serra y Veyrat, 2007), conceptos como turno e intervención, actos de habla, la comunicación verbal, el principio de cooperación, la gestión temática, la coherencia o la cohesión textual.

El primer capítulo se inicia con el análisis pragmático de hablantes afásicos no fluentes con el fin de verificar la relativa preservación de la pragmática que la literatura especializada les supone. En esta observación minuciosa se estudia la predictibilidad «cada turno puede imponer o no restricciones estructurales al turno posterior» (p. 55) y cómo esta característica estructural del lenguaje que los hablantes utilizan para encadenar sus intervenciones es manejada por los interlocutores-clave en sus conversaciones con los hablantes afásicos generando tipos de intervenciones muy concretas. Gallardo Paúls advierte que el estudio del tipo 
de intervención del hablante afásico nos va ayudar a reconocer su actitud dialógica: «Si un hablante presenta un predominio de turnos predichos, 'arrastrados' por la sintaxis desencadenante de los turnos ajenos, podemos deducir su resistencia a la actividad conversacional, y su repliegue comunicativo» (p. 60). En este capítulo se tratan, además, los efectos pragmáticos del agramatismo y la infradeterminación sintáctica en la construcción de los actos de habla.

El segundo capítulo se centra en la comunicación no verbal, una forma de comunicación imprescindible en aquellos tipos de afasia como la no fluente o motora que cursan con deficiencia en la movilidad. Siguiendo la visión semiótica de Eckman y Friesen (1969) se describen los principales gestos que aparecen en los hablantes estudiados (emblemas, ilustradores, reguladores) y que han sido codificados en el corpus PerLA constituyendo así una herramienta de indudable utilidad para el investigador, logopeda o lingüista interesado en su estudio.

La afasia fluente constituye el punto de partida del tercer capítulo en el que se nos expone la diferencia entre turno e intervención, así como la importancia del índice de participación conversacional y la agilidad de turno. Mediante el examen de estos elementos se puede observar, por ejemplo, la diferencia de ritmo coloquial respecto a la conversación ordinaria, ya que el intercambio dialógico del afásico no fluente se caracteriza por unos turnos excesivamente largos, con un alto porcentaje de las palabras totales presentes en dichos turnos, que lo convierten en «monopolizador» de la conversación, de ahí que sea tan importante tratar en la rehabilitación logopédica la gestión de la toma de turno y, por extensión, las normas que rigen el encadenamiento de las intervenciones.

La dificultad de aplicación de estas normas cooperativas que permiten a los hablantes dominar una serie de inferencias conversacionales llamadas implicaturas resulta, asimismo, pertinente en los hablantes con Síndrome de Williams abordados en el capítulo cuarto. Desde la óptica de la teoría de la enunciación de Benveniste y teniendo en cuenta las máximas conversacionales, las implicaturas generalizadas y anómalas y la gestión temática se llega a una descripción lingüístico-pragmática de tales hablantes que se caracterizarían por un déficit de intersubjetividad: «escasa topicalización de los temas ajenos, constante cambio de sujeto en los temas, ausencia de actos de habla proyectivos, escasos turnos predictivos, frecuencia de turnos sueltos...».

Los capítulos cinco y seis se centran en casos de niños con Trastorno por Déficit de Atención y/o Hiperactividad (TDAH) y lo hacen a partir de las narraciones elaboradas por estos niños en talleres de cuentos. El interés se localiza aquí en aspectos de pragmática textual: analizar los niveles estructurales del relato que soportan la coherencia y cohesión textuales, que en estos niños se muestran claramente como deficitarios.

En el último capítulo se resume el análisis pragmático pormenorizado que se ha llevado a cabo en los capítulos precedentes con la finalidad de demostrar que el déficit pragmático «permite una caracterización específica detallada y referida a todas las categorías pragmáticas de la lengua más allá de las descripciones intuitivas y faltas de rigurosidad; es además, un análisis que conjuga intencionadamente los méritos de la investigación cualitativa y cuantitativa» (p. 179).

Uno de los aspectos más destacables que se percibe a lo largo de toda la obra es el espíritu reivindicador de la Tercera Cultura, un matrimonio propuesto por C. P Snow en 1959 entre la cultura humanística y la científica que acabaría cristalizándose cuarenta años después en el libro de John Brockman, The Third Culture (1995). Es evidente que si en la comunicación humana cerebro, mente y lenguaje actúan conjuntamente (lo que Jean-Luc Nespoulous llama 
el dónde, el cómo y el qué) cualquier investigación exhaustiva del homo loquens debe contar con la participación de neurólogos, psicólogos, logopedas y lingüistas. Lo que este libro denuncia es que en la conceptualización del qué o lo lingüístico dichos conceptos teorizados no quedan claros, generalmente porque se ha hecho sin la intervención de los especialistas en la teoría lingüística, esto es, de los lingüistas (aunque no se entra a valorar si la escasa presencia de éstos viene dada por imposición o por desidia); de ahí, por ejemplo, que varios de los tests que manejan habitualmente logopedas y psicólogos se apoyen en conceptos difusos o malinterpretados.

Dentro de los parámetros de esta reflexión se destaca también el carácter secundario que lo escrito ostenta frente a lo oral, así como el predominio de esta modalidad (y de la sintaxis en sentido excesivamente formalista) en varios de tales repertorios logopédicos. Todo lo cual lleva a la autora a reiterar una y otra vez una idea que, por obvia, pasa desapercibida para los profesionales del lenguaje y sus patologías: la necesidad de contrastar los datos psicométricos (obtenidos mediante tests estandarizados) con la realidad del hablante. En este sentido, y como consecuencia de dicha reivindicación, Gallardo Paúls ha elaborado toda una monografía dentro del propio libro porque ha ido tomando como referencia un conjunto de tests y ha sabido valorar el campo real de actuación de los mismos. Esta dimensión se puede rastrear desde epígrafes concretos dedicados a las pruebas de evaluación hasta notas a pie de página. Evidentemente un test es más rápido y sencillo de «administrar» a un paciente, la pregunta que habría que hacerse es: ¿resulta realmente más fiable? Como ella misma confiesa no se trata de una animadversión hacia la medición psicométrica sino ante el hecho real de que esta medición no es complementada con la realidad lingüística del hablante.

Quizás el apartado pendiente de la obra sea el referido al concepto de déficit lingüístico y las incoherencias terminológicas abordado en la introducción, un cometido que, sin duda, requeriría una descripción aparte y probablemente sea de menor rentabilidad a corto plazo para el logopeda. Beatriz Gallardo insiste al respecto sobre la confusión «de la interpretación sintomática del déficit lingüístico con su interpretación como síndrome» y se atreve a dar una clasificación por niveles, estructuras y destrezas del mismo.

Creemos, por tanto, que este es un libro de obligada lectura no sólo para el logopeda sino para todo aquel que se interese por cuestiones de lingüística aplicada, en la medida en que los planteamientos iniciales se basan en los aspectos fundamentales de la teoría lingüísticopragmática de los últimos años. Se trataría, por ejemplo, de conocer qué es el principio de cooperación mediante la observación de éste en el Síndrome de Williams, o trabajar aspectos de coherencia y cohesión textuales a partir de narraciones de niños con TDAH, todo lo cual es más ilustrativo, pero también más difícil para quien lo investiga y desarrolla, que buscar ejemplos ad hoc que no encontramos nunca en contextos reales y que distorsionan la unidad imperiosa del discurso.

\section{Referencias bibliográficas}

Bennet, A.(1994): Writing home. Londres, Faber and Faber.

Brockman, J. (1995): The Third Culture: Beyond Scientific Revolution. Nueva York, Touchstone.

Eckman, P. y W. V. Friesen (1969): «The repertoire of Nonverbal Behavior: categories, origins, usage and coding», Semiotica, 1969/1, págs. 49-98. 
Gallardo Paúls, B. y V. Moreno (2005): Afasia no fluente. Materiales y análisis pragmático. Valencia, Universitat/ AVaLCC.

Gallardo Paúls, B. y J. Sanmartín (2005): Afasia fluente. Materiales para su estudio. Valencia, Universitat-AVaLCC.

Garayzábal Heinze, E. (2005): Síndrome de Williams. Materiales y análisis pragmático. Valencia, Universitat-AVaLCC.

Hernández Sacristán, C., Serra, E. y M. Veyrat (2007): Afasia: casos mixtos. Materiales y análisis lingüistico. Valencia, Universitat-AVaLCC.

Parkin, A. J. (1999): Exploraciones en neuropsicología cognitiva. Barcelona, Panamericana. 